\title{
Research Paper: Exploring the Challenges in Orthotics and Prosthetics Clinical Learning Environments: A Qualitative Study
}

\author{
Saeed Shahabi ${ }^{1,2}$ (D, Mohammad Kamali ${ }^{1,3^{*}}$, Hossein Mobaraki ${ }^{1,3}$, Narges Shafaroodi ${ }^{4} \mathbb{D}$, Hassan Saeedi ${ }^{3,5}$ (D) \\ 1. Department of Rehabilitation Management, School of Rehabilitation Sciences, Iran University of Medical Sciences, Tehran, Iran. \\ 2. Health Management and Economics Research Center, Iran University of Medical Sciences, Tehran, Iran. \\ 3. Rehabilitation Research Center, Iran University of Medical Sciences, Tehran, Iran. \\ 4. Department of Occupational Therapy, School of Rehabilitation Sciences, Iran University of Medical Sciences, Tehran, Iran \\ 5. Department of Orthotics and Prosthetics, School of Rehabilitation Sciences, Iran University of Medical Sciences, Tehran, Iran.
}

\begin{tabular}{l|l}
$\begin{array}{c}\text { Use you devict to san } \\
\text { and read theartice online }\end{array}$ & $\begin{array}{l}\text { Citation Shahabi S, Kamali M, Mobaraki H, Shafaroodi N, Saeedi H. Exploring the Challenges in Orthotics and Prosthet- } \\
\text { ics Clinical Learning Environments: A Qualitative Study. Iranian Rehabilitation Journal. 2019; 17(1):31-38. http://dx.doi. } \\
\text { org/10.32598/irj.17.1.31 }\end{array}$ \\
doi http://dx.doi.org/10.32598/irj.17.1.31
\end{tabular}

Article info:

Received: 13 Aug 2018

Accepted: 29 Dec 2018

Available Online: 01 Mar 2019

\section{Keywords:}

Challenges, Clinical learning environment, Clinical educator, Orthotics, Prosthetics, Qualitative study

\section{A B STRACT}

Objectives: The present study explored challenges in orthotics and prosthetics clinical learning environments in Iran.

Methods: A qualitative content analysis method was used to obtain data on orthotics and prosthetics clinical educator's experiences. Qualitative data were obtained using semistructured in-depth interviews involving 7 clinical educators; all selected by the maximum variation purposeful sampling method. Interviews continued until data saturation.

Results: During the interview sessions, notes and ideas were classified and assorted. The study themes were relationships, personal characteristics, facilities, and policies. Analysis of the qualitative data provided insights into the barriers to the desired delivery of clinical education services.

Discussion: The present research contributes to clinical educators' experiences in respect of the clinical learning process. Clinical learning concerning orthotics and prosthetics education remains crucial. The findings emphasize the importance of listening to educators, and consider how relationships and contexts impact clinical learning. Understanding the challenges in clinical education environments has increased the quality of clinical education in orthotics and prosthetics field. 


\section{Highlights}

- Interpersonal and group relationships affect the quality of clinical education.

- Individual and professional characteristics of students and clinical educators influence clinical learning.

- Another important factor is the characteristics of the clinical environment and facilities.

\section{Plain Language Summary}

The provision of orthotic and prosthetic services requires the presence of skilled therapists. Clinical education is one of the main pillars of orthotics and prosthetics. Providing educational services to students is done by clinical educators who are responsible for both healthcare provision to clients, and clinical education to students. Clinical education occurs in an environment where the provision of services to clients leads to human resource limitations and fiscal pressure. Therefore, recognizing the experiences of clinical educators from the clinical education process can provide the necessary ground for improving clinical education in the field of orthotics and prosthetics.

\section{Introduction}

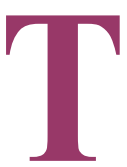

he fulfillment of clinical placements and exercising supervision play a key role in healthcare students' achievement of desired learning outcomes $[1,2]$, the growth of their professional characteristics and capability [3], as well as mastering their clinical skills [4]. Clinical education, which is a kind of learning through experience, includes mastering clinical skills at work. Clinical education is the best option for beginners to enhance their clinical reasoning expertise [5].

In clinical teaching, teachers are required to consider the right developmental level of each learner and empower their participation in workplace activities appropriate to their stage of learning [6]. The development of capable rehabilitation therapists like orthotics and prosthetics requires clinical practice experience at the undergraduate level.

Successful clinical education depends s on the clinical educators, their capabilities and personal characteristics, and the support and encouragement they receive [7]. Clinical learning involves obtaining clinical experience and practicing the necessary skills through observation, participation, designing the treatment methods and applying it by considering all the clinical aspects, under the supervision of a teacher [8].

In spite of the importance of orthotics and prosthetics clinical education, there is a lack of clear understanding of assisting individuals involved in clinical instruction. When students join the clinical environment, they are faced with patient's healthcare needs and their learning needs. Learning may improve in an appropriate clinical environment. The clinical environment is ideal for education [9]. Clinical education of orthotics and prosthetics students is conducted at three medical universities and the Iranian Red Crescent Institute (IRCI). Typically, orthotics and prosthetics student's clinical practice initiates from the fifth and sixth semesters with observation courses. Then, students enroll the internship courses [10].

Several studies have suggested that learning environments greatly influence the clinical education process [11]. The clinical environment includes inpatient centers, as well as hospital outpatient and community settings, with their own specific issues. Researchers have repeatedly emphasized that the quality of clinical education environment is a strong reliable indicator of the overall quality of training courses [12].

Clinical educators are responsible for healthcare provision to clients, and clinical education to students, simultaneously. Clinical education occurs in an environment where the provision of services to clients leads to human resource limitations and fiscal pressures [13]. Therefore, the present research explored orthotics and prosthetics educators' experiences in clinical learning environments in Iran.

\section{Methods}

This qualitative study was performed using content analysis method. Qualitative research clarifies the human condition in various contexts [14]. Qualitative 
Content Analysis (QCA) is usually used to explain the textual data by applying the systematic coding process. Data analysis characterizes the categories, themes, and patterns [15]. QCA consists of conventional (inductive), directed (deductive) and summative methods [16]. Inductive QCA, which is most favored in data analysis, contributes to the improvement of theories, schematic models or conceptual frameworks [17].

\section{Sampling and data collection methods}

For participant recruitment, maximum variation and purposive sampling methods were applied. This purposive sampling technique was specifically selected to ensure that the sample population would represent various factors relevant to the study objectives [18]. The study was performed from September 2016 to May 2017. Semi-structured interviews were performed, recorded and completely transcribed by 7 orthotics and prosthetics clinical educators affiliated to Iran University of Medical Sciences (IUMS), Isfahan University of Medical Sciences (MUI), University of Social Welfare and Rehabilitation Sciences (USWR), and IRCI (Table 1).

All interviews were conducted by the same researcher and continued until data saturation. In addition, the researcher recorded respondents' body language and verbal information. The inclusion criteria for clinicians were $\geq 3$ years of clinical education experience and providing clinical education services to students, during the research period. Prior to the beginning of each interview, the researcher informed the participants about the purpose of study and their right to withdraw from the study as desired.

The interview included open-ended questions on orthotics and prosthetics clinical educators' experience regarding their clinical learning environment and factors influencing their clinical learning process. A guide was developed for the semi-structured interviews, and the following questions were asked, which focused on the participants' experiences as clinical educators: 1 . Describe an internship session; 2. What are the positive or negative factors for clinical learning?; 3 . What is the most enjoyable moment or event that has been implicated in your mind in the clinical environment?; and 4. What are the factors that can influence the formation of a person as orthotics and prosthetics?

The interviews lasted for 43-65 min, with a mean duration of $52.7 \mathrm{~min}$. Exclusion criterion was the participant's relinquishment in any step of the study.

\section{Ethical considerations}

The study was approved by the Research Ethics Committee of Iran University of Medical Sciences (Code: IR.IUMS.REC 1395.9411531004). The study was conducted following the instructions issued by the Declaration of Helsinki (2008): The participants were briefed on the study both verbally and in writing. The study participants provided written informed consent forms prior to the interviews. To protect their privacy and confidentiality, all data were recorded anonymously.

\section{Data credibility}

Activities such as peer debriefing, prolonged engagement, persistent observation, triangulation, negative case analysis, referential adequacy, and member checking can be used to build credibility [19]. The research credibility was checked. Participants', investigators' and method triangulations were done to ensure the precision and reliability of this qualitative study.

\section{Data analysis}

The semi-structured interviews were tape-recorded and transcribed; then, the transcriptions were analyzed using content analysis method. It is often appropriate that existing theories or literature be limited to the studied phenomenon. The analysis was conducted manually. Due to long-term engagement with the study participants and obtained data, the researchers effectively communicated with the study participants and thoroughly understood the study context. The transcribed interviews were read and re-read to obtain a clear statement by the researchers. According to the study objectives, meaning units were identified, composed and coded. In total, 116 open codes were extracted. The codes were classified into different categories. Finally, as per Table 2, the meaningful themes were obtained by comparing the orthotics and prosthetics clinical educators' experiences categories.

\section{Results}

Seven individual interviews were completed. Some characteristics of the study participants and interviews are presented in Table 1. The analysis yielded four themes of relationships, personal characteristics, facilities, and policies (Table 2).

\section{Relationships}

This was the first theme extracted from the data and consisted of "relationship between students and clinical 
Table 1. Characteristics of participants and interviews

\begin{tabular}{cccccc}
\hline Interview & University & Gender & Education History, Y & Time, Min & Codes \\
\hline 1 & IUMS & Female & 4 & 65 & 30 \\
2 & IRCI & Male & 11 & 51 & 23 \\
\hline 3 & IUMS & Male & 5 & 55 & 20 \\
4 & MUI & Female & 13 & 50 & 16 \\
5 & USWR & Male & 13 & 43 & 13 \\
7 & USWR & Male & 6 & 45 & 8 \\
& IRCI & Female & 12 & 60 & 6 \\
\hline
\end{tabular}

Iranian Rehabilitation Journal

educators", "relationship between students" and "relationship between students and patients". All clinical educators reported relationships as a stressor source in clinical environments. The study participants expressed different dimensions of relationships between students and patients and even their companions, effective in clinical learning processes.

A number of contributors mentioned the positive impact of group relationships on the educational process. One of the clinical educators indicated the impact of se-

Table 2. Themes and categories derived from interviews nior students on junior students, which could negatively affect the educational process in clinical settings: "In the prosthetic section, senior students are together with lower grade students in a course ... But, they always disappoint new students!" [CE6, line 3].

The communication and interaction of healthcare center staff with the students are effective in the clinical education process and cause a variety of experiences to students: "some of my colleagues find students disturb-

\begin{tabular}{|c|c|}
\hline Theme & Category \\
\hline \multirow{3}{*}{ Relationships } & Relationship between students and clinical educators \\
\hline & Relationship between students \\
\hline & Relationship between students and patients \\
\hline \multirow{3}{*}{ Personal characteristics } & Individual characteristics of students \\
\hline & Personal and professional characteristics of clinical educators \\
\hline & Patient's characteristics \\
\hline \multirow{3}{*}{ Facilities } & Physical characteristics of the clinical center \\
\hline & Environmental health \\
\hline & Environmental safety \\
\hline \multirow{3}{*}{ Policies } & Ministry of health policies \\
\hline & University approaches \\
\hline & Educational department approaches \\
\hline
\end{tabular}

Iranian Rehabilitation Journal 
ing their work at clinical centers ... they believe their time is wasted!" [CE 5, line 21].

A number of participants objected to the clarity of boundaries of orthotics and prosthetics, compared with other areas of rehabilitation. This can interfere with tasks while performing team work: "e.g. physiotherapists can prescribe orthoses, but not us! now, students are discouraged ..." [CE 3, line 19].

The role of mentor support in the process of clinical education is very important. One of the clinical educators believed that: " ... indeed, students must be supported at work. I always prefer to help them. Sometimes, in the middle of the work, I assist them with their work" [CE 6 , line 5]

\section{Personal characteristics}

This theme consists of three categories, as follows: "the individual characteristics of students", "the personal and professional characteristics of clinical educators", and "patient's characteristics".

Student motivation significantly impacts the clinical education process. "[students] do not want to do anything. [they] come sit and drink tea ... [laughter]" [CE2, line 5].

One of the educators also mentioned the lack of accuracy among clinical instructors during internships and believed there should be a firm structure: “... we have less accuracy and less stringency than physiotherapist" [CE 7, line 20].

Contributors discussed the negative impact of job conditions on clinical education, as follows: "I'm getting the money for every orthosis I make ... well, naturally, I try to work harder, to earn more! This condition limits my internship attendance" [CE 5, line 3].

In clinical education, the educator should communicate with students to transfer knowledge and skills. Self-esteem and students' learning identity are preserved: “... when you appreciate the students' work, their efforts and motivations are reinforced" [CE 6, Line 10]. Constant monitoring of clinical instructors is effective in trainees' performance. This was another matter expressed by a number of contributors: "it is necessary to pay attention to the students' work ..." [CE 2, line 21].

Referring patients to medical education centers as affects the clinical environment with the following condi- tions and characteristics: awareness level, socio-political status, psychological features and personal hygiene. The personal hygiene of clients referred to rehabilitation centers is important: "the socks of a patient were so dirty! Students could not approach him ..." [CE 6, line 23].

Some participants discussed the impact of socio-political status of patients on the clinical education process: "e.g. if the patient is a mayor, the girls are not allowed to visit him! He says only boys ..." [CE 3, line 4]. Mistrust of patients on trainees does not allow them to sufficiently cooperate and disrupt the training process.

\section{Facilities}

The characteristics of clinical environment are discussed in various methods by the study participants. This theme is also composed of three categories, as follows: "the physical characteristics of clinical center", "environmental health", and "environmental safety". Unlike other medical sciences, in the field of orthotics and prosthetics, most of the work is demonstrated in technical workshops. Therefore, proper equipment and tools are essential for the supply of qualitative orthoses and prostheses.

Many clinical trainers have reported that the tools of educational centers are outdated: "we lack modern devices in the department! We have a force plate ... which is always broken!" [CE 7. line 12].

In this field, the presence of raw materials for the construction of orthoses and prostheses is among the main components of clinical education process. In some centers, the lack of raw materials or difficulty in obtaining those are students' challenges in clinical learning. One of the educators complained about the limited space of clinic and the inappropriateness of physical space with the number of students: "the problem is ... the workshop is small ... it is chaotic!" [CE3, line11].

The use of equipment and tools such as sandblast, grinding, and gibson machines, hammers, as well as raw materials such as laminate and carbon, affect the workplace environment. The presence of various tools at orthotics and prosthetics workshops requires the observance of safety principles. However, a number of contributors mentioned the negative attitudes in the use of protective equipment in clinical settings: “... some people tell students that the use of protective devices is ridiculous!" [CE 3, line 3]. 


\section{Policies}

The last theme focuses on the factors impacting the student's learning process despite the high spatial and temporal distance from the clinical education environment. This theme consists of three categories, as follows: "the Ministry of health policies", "university approaches" and "educational department approaches".

There are numerous upstream laws and policies that somehow affect the quality and effectiveness of internships and students' experiences. In the past few years, the Ministry of Health has privatized health and rehabilitation centers. A number of educators emphasized on the negative impact of this approach on clinical education: "now we cannot refer students to hospital centers because they are private ..." [CE 7, line 9].

One of the educators also objected to extensive admission of students. "Too many students are admitted. We cannot teach them well" [CE 1, line 25].

The method of allocating financial and non-financial resources among the departments of the university affects the availability of facilities and functions of clinical environments. A contributor expressed his objection as follows: "they do not allocate us enough budget to buy instruments and materials!” [CE 1, line 8].

Educational departments provide high quality educational services to students. Some clinical educators believed that the theoretical units were high and not proportional to practical units. The result is confusion among students in clinical settings: “... some theoretical lessons are not used in the clinical setting!" [CE 4, line 22].

\section{Discussion}

This study aimed to discuss orthotics and prosthetics clinical educators' experiences on challenges in clinical environments and settings. The study participants stated that positive relationships between students improve the learning process. Research has also revealed that the peer-assisted learning approach apparently decreases the students' anxiety, improves their sense of safety in the learning environment, decreases educators' responsibilities and enhances professional skills like cooperation [20-22]. The negative effects of senior students on other students and their pessimism and disappointment are in line with the results of this study. However, a number of studies have explained how a positive relationship between peers improves the learning process $[23,24]$
The current study suggests that appropriate relationships between students and staff is effective in the clinical education process. Previous studies have also highlighted the importance of social dimension of clinical education environments [25]. Teamwork requires clear roles and responsibilities of various professionals. In this study, it was stated that the uncertainty of the boundaries of field is conflicting. Therefore, the knowledge of different professionals from their duties and inter-professional collaboration positively affects the atmosphere of clinical education [26].

In this research, a number of contributors indicated the impact of mentorship and receiving feedbacks from clinical educators during the clinical education process. Mentoring opportunities may be structured for orthotics and prosthetics students to facilitate clinical decisionmaking and reflection skills [27, 28].

Clinical educators identified a range of characteristics exhibited by their students, including interest, motivation, attitude, and desire to perform technical work affecting the student's active presence in clinical settings. Studies have reported that lack of student motivation to learn, and their irresponsibility and irregularity, affect clinical education $[24,29]$.

The findings indicate that the status of clinical educators' occupation is one of the challenges in clinical settings. This is because they pay attention to the students' learning needs and the patients' needs, simultaneously. This suggestion is likely associated with low salaries in academia and how these low salaries are a disincentive for recruitment and retention [30]. In clinical training, educators' interaction with students is a significant chance of learning. Based on the obtained data, respecting students' learner identities in clinical settings increases their effort and motivation [31].

The obtained results suggested that the of patients' characteristics and relatives may negatively impact the clinical education process. The relatives' overprotective attitudes and patients' distrust unable students to well perform their duties and negatively impact their performance.

Clinical educators who participated in the study indicated that the number of students are too high and the available facilities are not adequate for the number of accepted students. Many students would probably assume that clinical instructors might not have enough time for them and being evaluated incorrectly is the issue that worries these students most $[32,33]$. 
Observance of hygiene issues and safety principles are among the necessities of clinical training centers for orthosis and prosthesis courses. This is a result not reported by previous studies. Thus, paying attention to the students' health should be prioritized. Finally, the lack of coordination between theoretical and practical lessons leads to different perceptions in clinical education environments. The literature review suggests that a significant amount of stress is caused due to the gap between theory and practice during clinical practices [34].

\section{Conclusion}

Results of this study suggest considering the challenges in orthotics and prosthetics clinical education environments, provides the necessary conditions for improving the quality of educational services and, consequently, providing graduates with effective training. Clinical learning with regards to orthotics and prosthetics education remains crucial. The findings emphasize the importance of listening to educators, considering how relationships and contexts impact clinical learning. In this study, clinical educators could not be gathered at a meeting, simultaneously. As a result, focus group discussions could not be conducted.

\section{Ethical Considerations}

\section{Compliance with ethical guidelines}

The study was approved by the Research Ethics Committee of Iran University of Medical Sciences (code: IR.IUMS.REC 1395.9411531004). The study was conducted following the instructions issued by the Declaration of Helsinki (2008): The participants were briefed on the study both verbally and in writing; The study participants provided written informed consent forms prior to the interviews; To protect their privacy and confidentiality, all data were recorded anonymously.

\section{Funding}

The present paper was extracted from the MSc. thesis of the first author, in Department of Rehabilitation Management, School of Rehabilitation Sciences, Iran University of Medical Sciences.

\section{Authors contributions}

Conceptualization: Saeed Shahabi and Mohammad Kamali; Methodology: Saeed Shahabi and Narges Shafaroodi; Interviews: Saeed Shahabi; Writing-original draft: All Authors; Writing-review \& editing: All authors; and Supervision: Mohammad Kamali.

\section{Conflict of interest}

The authors declared no conflict of interest.

\section{Acknowledgements}

We would like to appreciate the participants, orthotics and prosthetics clinical educators, whose support made conducting this study possible.

\section{References}

[1] Cooper J, Courtney-Pratt H, Fitzgerald M. Key influences identified by first year undergraduate nursing students as impacting on the quality of clinical placement: A qualitative study. Nurse Education Today Journal. 2015; 35(9):1004-8. [DOI:10.1016/j.nedt.2015.03.009] [PMID]

[2] Dimitriadou M, Papastavrou E, Efstathiou G, Theodorou M Baccalaureate nursing students' perceptions of learning and supervision in the clinical environment. Nursing \& Health Sciences. 2015; 17(2):236-42. [DOI:10.1111/nhs.12174] [PMID]

[3] Newton JM, Jolly BC, Ockerby CM, Cross WM. Clinical learning environment inventory: Factor analysis. Journal of Advanced Nursing. 2010; 66(6):1371-81. [DOI:10.1111/j.13652648.2010.05303.x] [PMID]

[4] Saarikoski M, Warne T, Kaila P, Leino-Kilpi H. The role of the nurse teacher in clinical practice: An empirical study of Finnish student nurse experiences. Nurse Education Today Journal. 2009; 29(6):595-600. [DOI:10.1016/j.nedt.2009.01.005] [PMID]

[5] Ryan S, Higgs J. Teaching and learning clinical reasoning. In: Higgs J, Jones M, Loftus S, Christensen N, editors. Clinical Reasoning in the Health Professions. Oxford: ButterworthHeinemann; 2008.

[6] Ramani S, Leinster S. AMEE guide no. 34: Teaching in the clinical environment. Medical Teacher. 2008; 30(4):347-64. [DOI:10.1080/01421590802061613] [PMID]

[7] Higgs J, Mcallister L. The lived experiences of clinical educators with implications for their preparation, support and professional development. Learning in Health and Social Care 2005; 4(3):156-71. [DOI:10.1111/j.1473-6861.2005.00097.x]

[8] Gaberson K, Oermann M. Clinical teaching strategies in nursing. New York City: Springer Publishing; 2010.

[9] Atack L, Comacu M, Kenny R, LaBelle N, Miller D. Student and staff relationships in a clinical practice model: Impact on learning. Journal of Nursing Education. 2000; 39(9):387-92. [PMID]

[10] Department of Technical Orthopedic. Headlines lessons of Technical Orthopedic. Tehran: University of Social Welfare and Rehabilitation Sciences; 2012. 
[11] Andrews G, Brodie DA, Andrews JP, Hillan E, Gail Thomas B, Wong J, et al. Professional roles and communications in clinical placements: A qualitative study of nursing students' perceptions and some models for practice. International Journal of Nursing Studies. 2006; 43(7):861-74. [DOI:10.1016/j. ijnurstu.2005.11.008] [PMID]

[12] Mohamadpour $Y$, Habibzadeh H, Khalilzadeh H, Pakpour $\mathrm{V}$, Jafarizadeh $\mathrm{H}$, Rafiee $\mathrm{H}$ et al. [Nursing students' perceptions of their educational environment: A comparison between expected and actual environment (Persian)]. Journal of Urmia Nursing and Midwifery Faculty. 2011; 9(2):102-11.

[13] Lo K, Curtis H, Keating JL, Bearman M. Physiotherapy clinical educators' perceptions of student fitness to practise. BMC Medical Education. 2017; 17:16. [DOI:10.1186/s12909016-0847-2] [PMID] [PMCID]

[14] Bengtsson M. How to plan and perform a qualitative study using content analysis. Nursing Plus Open. 2016; 2:8-14 [DOI:10.1016/j.npls.2016.01.001]

[15] Zhang Y, Wildemuth BM. Qualitative analysis of content. Analysis. 2005; 1(2):1-12. [DOI:10.1002/hbm.20661]

[16] Mayring P. Qualitative content analysis: Theoretical foundation, basic procedures and software solution. Cologne, Germany: Social Science Open Access Repository; 2014.

[17] Vaismoradi M, Jones J, Turunen H, Snelgrove S. Theme development in qualitative content analysis and thematic analysis. Journal of Nursing Education and Practice. 2016; 6(5):10010. [DOI:10.5430/jnep.v6n5p100]

[18] Hsieh HF, Shannon SE. Three approaches to qualitative content analysis. Qualitative Health Research. 2005; 15(9):1277-88. [DOI:10.1177/1049732305276687] [PMID]

[19] EloS, Kääriäinen M,KansteO,Pölkki T,Utriainen K, Kyngäs H. Qualitative Content Analysis: A focus on trustworthiness. SAGE Open. 2014; 4(1). [DOI:10.1177/2158244014522633]

[20] Sevenhuysen S, Farlie MK, Keating JL, Haines TP, Molloy E. Physiotherapy students and clinical educators perceive several ways in which incorporating peer-assisted learning could improve clinical placements: A qualitative study. Journal of Physiotherapy. 2015; 61(2):87-92. [DOI:10.1016/j. jphys.2015.02.015] [PMID]

[21] Mori B, Carnahan H, Herold J. Use of simulation learning experiences in physical therapy entry-to-practice curricula: A systematic review. Physiotherapy Canada. 2015; 67(2):194202. [DOI:10.3138/ptc.2014-40E] [PMID] [PMCID]

[22] Gard G, Dagis D. Physiotherapy students' perceptions of learning in clinical practice in Sweden and India. Nurse Education Today. 2016;36:381-6. [DOI:10.1016/j.nedt.2015.10.001] [PMID]

[23] Zapko KA, Ferranto ML, Blasiman R, Shelestak D. Evaluating best educational practices, student satisfaction, and selfconfidence in simulation: A descriptive study. Nurse Education Today. 2018; 60:28-34. [DOI:10.1016/j.nedt.2017.09.006] [PMID]

[24] Nodehi Moghadam A, Abdi K, Kashfi Ardehjan P. Exploring the challenges of physiotherapy clinical education: A qualitative study. Iranian Rehabilitation Journal. 2017; 15(3):207-14. [DOI:10.29252/nrip.irj.15.3.207]
[25] O'Mara L, McDonald J, Gillespie M, Brown H, Miles L. Challenging clinical learning environments: Experiences of undergraduate nursing students. Nurse Education in Practice. 2014; 14(2):208-13. [DOI:10.1016/j.nepr.2013.08.012] [PMID]

[26] Lockeman KS, Appelbaum NP, Dow AW, Orr S, Huff TA, Hogan CJ, et al. The effect of an interprofessional simulationbased education program on perceptions and stereotypes of nursing and medical students: A quasi-experimental study. Nurse Education Today. 2017; 58:32-7. [DOI:10.1016/j. nedt.2017.07.013] [PMID]

[27] Dahlke S, O'Connor M, Hannesson T, Cheetham K. Understanding clinical nursing education: An exploratory study. Nurse Education in Practice. 2016; 17:145-52. [DOI:10.1016/j. nepr.2015.12.004] [PMID]

[28] Wainwright SF, Shepard KF, Harman LB, Stephens J Novice and experienced physical therapist clinicians: A comparison of how reflection is used to inform the clinical decision-making process. Physical Therapy. 2010; 90(1):75-88. [DOI:10.2522/ptj.20090077] [PMID]

[29] Kamali M, Dastgheibi SMR, Chabok A, Dadgoo M, Ghanaatian S. [Physiotherapy students'experiences from clinical education processes: A qualitative study (Persian)]. Journal of Research in Rehabilitation Sciences. 2013; 9(5):818-32.

[30] Laurencelle FL, Scanlan JM, Brett AL. The meaning of being a nurse educator and nurse educators' attraction to academia: A phenomenological study. Nurse Education Today. 2016; 39:135-40. [DOI:10.1016/j.nedt.2016.01.029] [PMID]

[31] Vameghi R, Seyyedi A, Adibsereshki N, Abdi K. Validity and reliability of general evaluation tool for clinical training in rehabilitation disciplines. Iranian Rehabilitation Journal. 2015; 13(4):34-9.

[32] Karaöz S. Overview clinical evaluation of nursing education: Challenges and recommendations. Dokuz Eylül Üniversitesi. 2013; 6(3):149-58.

[33] Shokooh F, Hossaini MA, Mohammadi F, Rahgozar M. Comparing faculty and students perceptions on clinical competency achievement in rehabilitation programs. Iranian Rehabilitation Journal. 2009; 7(2):20-4.

[34] Arkan B, Ordin Y, Yılmaz D. Undergraduate nursing students' experience related to their clinical learning environment and factors affecting to their clinical learning process. Nurse Education in Practice. 2018; 29:127-32. [DOI:10.1016/j. nepr.2017.12.005] [PMID] 